\title{
PERENCANAAN POLIKLINIK JIWA DI SAMARINDA PENEKANAN PADA ORGANISASI RUANG
}

\author{
Nur Husniah Thamrin \\ Staf Pengajar Jurusan Desain, PS. Arsitektur, Politeknik Negeri Samarinda \\ Email :nhusniah62@gmail.com \\ Zakiah Hidayati \\ Staf Pengajar Jurusan Desain, PS. Arsitektur, Politeknik Negeri Samarinda \\ Email: zakitec@gmail.co \\ Ayu Lestari \\ Mahasiswa Jurusan Desain, PS. Arsitektur, Politeknik Negeri Samarinda \\ Email: iuree197@gmail.com
}

\begin{abstract}
The Mental Polyclinic in Samarinda is a health facility that focuses on mental disorders, namely schizophrenia. The purpose of this design is to realize a health facility for people with schizophrenia with adequate facilities and infrastructure. The design of the polyclinic that supports the concept of spatial planning is space organization to provide convenience for its users. Given that the facilities and infrastructure needed for sufferers of mental disorders are important, therefore space organizations need to be considered well so as not to endanger patients. The architectural style used is modern tropical architecture to support the concept of a therapeutic garden that will be used to support the recovery of patients. This design uses field observations and interviews to obtain data and information. So that a site location is obtained that is in accordance with the design of the Soul Polyclinic with a strategic site for the location of trade and services in Samarinda City.
\end{abstract}

Keywords: Soul, polyclinic, space

\begin{abstract}
ABSTRAK
Poliklinik Jiwa di Samarinda merupakan sebuah fasilitas kesehatan yang berfokus kepada gangguan jiwa yaitu skizofrenia. Adapun tujuan dari perancangan ini adalah untuk mewujudkan sebuah fasilitas kesehatan bagi penderita skizofrenia dengan sarana dan prasarana yang memadai. Perancangan poliklinik yang mendukung konsep penyusunan ruang yaitu organisasi ruang untuk memberikan kenyamanan bagi penggunanya. Mengingat bahwa sarana dan prasarana yang dibutuhkan bagi penderita gangguan jiwa merupakan hal yang penting, maka dari itu organisasi ruang perlu diperhatikan dengan baik agar tidak membahayakan pasien. Gaya arsitektur yang digunakan yaitu arsitektur modern tropis untuk mendukung konsep taman terapeutik yang akan digunakan untuk mendukung kesembuhan pasien.

Perancangan ini menggunakan observasi lapangan dan wawancara untuk mendapatkan data dan informasi. Sehingga diperoleh sebuah lokasi site yang sesuai dengan perancangan Poliklinik Jiwa dengan site yang strategis untuk lokasi perdagangan dan jasa di Kota Samarinda.
\end{abstract}

Kata kunci : jiwa, poliklinik, ruang 
Nur Husniah Thamrin, Zakiah Hidayati, Ayu Lestari, Perencanaan Poliklinik Jiwa di

Samarinda, Penekanan Pada Organisasi Ruang

\section{PENDAHULUAN}

Kesehatan jiwa adalah bagian penunjang terwujudnya kualitas hidup manusia yang utuh. Undang -Undang Nomor 36 Tahun 2009 tentang Kesehatan Pasal 144 Ayat 1 menyatakan, menjamin setiap orang dapat menikmati kehidupan yang sehat, bebas dari ketakutan, tekanan, dan gangguan jiwa yang lain dapat mengganggu kesehatan jiwa.

Kalimantan Timur menempati peringkat ke-17 dengan daerah yang memiliki penderita depresi terbanyak di Indonesia. Berdasarkan Profil Kesehatan Samarinda pada tahun 2016, jumlah pasien gangguan jiwa di Kota Samarinda mencapai 1.050 pasien. Data lain menunjukkan sebanyak 5\% penduduk Kaltim menderita skizofrenia, itu artinya sebanyak 175.400 penderita. Berdasarkan data RSJ Atma Husada Samarinda, jumlah kunjungan dan pasien rawat inap sebagian besar adalah penderita skizofrenia. Pada tahun 2017 tercatat sebanyak 15.201 pasien rawat jalan, lalu meningkat di tahun 2018 menjadi 15.847 pasien.

Skizofrenia adalah sekelompok gangguan psikotik dengan distorsi khas proses piker, kadang-kadang mempunyai perasaan bahwa dirinya sedang dikendalikan oleh kekuatan di luar dirinya, waham yang kadang-kadan aneh, gangguan persepsi, afek abnormal yang tergabung dengan situasi nyata atau sebenarnya, dan autisme (Zahnia, Wulan, 2016). Rumah Sakit Atma Husada Mahakam yang ada di Samarinda memiliki fasilitas yang lengkap dapat menampung sebanyak 250 pasien. Mengingat pasien yang datang tidak hanya berasal dari Samarinda serta tingkat penderita yang semakin bertambah, daya tampung ini terbilang sangat kecil.

Pada perancangan kali ini lokasi yang akan digunakan berada di Jalan D.I. Panjaitan, Samarinda. Di sekitar lokasi merupakan area pemukiman serta perdagangan yang ramai tetapi fasilitas kesehatan yang serupa berada cukup jauh sehingga hal ini menjadi potensi. Organisasi ruang menjadi penekanan pada perancangan hal ini dikarenakan pada Poliklinik Jiwa Samarinda ingin dibangun sebuah tempat yang dapat membangun interaksi sosial baik penderita maupun pengguna bangunan lainnya. Organisasi ruang yang baik dan tepat akan menciptakan lingkungan yang baik pula.

\section{Poliklinik}

Poliklinik atau instalasi rawat jalan merupakan skala kecil dari pelayanan kesehatan yang memiliki fungsi hampir sama dengan rumah sakit. Dalam peraturan menteri kesehatan RI nomor 920/Menkes/Per/ XII/1986 Klinik atau Poliklinik Jiwa adalah sarana layanan kesehatan jiwa yang diberikan kepada masyarakat. Penyelenggaraan klinik atau poliklinik jiwa dilaksanakan oleh pemerintah dan swasta, di mana klinik swasta dapat berupa praktek berkelompok maupun perorangan.

\section{Gangguan Jiwa}

Gangguan jiwa adalah gangguan dalam cara berpikir (cognitive), kemauan (volition), emosi (affective), tindakan (psychomotor). Kumpulan dari keadaankeadaan yang tidak normal, baik yang berhubungan dengan fisik, maupun dengan mental. Keabnormalan tersebut yaitu:gangguan jiwa (Neurosa) dan sakit jiwa (psikosa). Keabnormalan terlihat dalam berbagai macam gejala yang terpenting diantaranya adalah:ketegangan (tension), rasa putus asa dan murung, gelisah, cemas, perbuatan-perbuatan yang terpaksa (convulsive), hysteria, rasa lemah, tidak mampu mencapai tujuan, takut, pikiran-pikiran buruk (Yosep, 2007 dalam Nopyawati Sulistyorini, 2013).

Penderita gangguan jiwa sering mendapatkan stigma dan diskriminasi yang lebih besar dari masyarakat disekitarnya dibandingkan individu yang menderita penyakit medis lainnya. Tidak hanya menimbulkan konsekuensi negatif terhadap penderitanya tetapi juga bagi anggota keluarga, meliputi sikapsikap penolakan, penyangkalan, dan disisihkan. Penderita ganggu- 
Vol. 7, No. 1, Oktober 2019

an jiwa mempunyai resiko tinggi terhadap pelanggaran hak asasi manusia (Priyanto, 2007 dalam Nopyawati Sulistyorini,2013). Mereka sering sekali disebut sebagai orang gila (insanity atau madness).

Perlakuan ini disebabkan karena ketidaktahuan atau pengertian yang salah dari keluarga atau anggota masyarakat mengenai gangguan jiwa. Gangguan jiwa dapat mempengaruhi fungsi kehidupan seseorang. Aktivitas, kehidupan sosial, ritme pekerjaan, serta hubungan dengan keluarga jadi terganggu karena gejala ansietas, depresi, dan psikosis. Seseorang dengan gangguan jiwa apapun harus segera mendapatkan pengobatan. Keterlambatan pengobatan akan semakin merugikan penderita, keluarga dan masyarakat (Yosep, 2010 dalam Nopyawati Sulistyorini,2013)

\section{Organisasi Ruang}

Organisasi Ruang D.K. Ching (1996) menyebutkan bahwa organisasi ruang dapat dibagi menjadi 5 bagian, yaitu :

\section{a. Organisasi linear}

Suatu urutan dalam satu garis dari ruang-ruang yang berulang. Bentuk organisasi linear bersifat flexsibel dan dapat menanggapi terhadap bermacam-macam kondisi tapak.

\section{b. Organisasi radial}

Organisasi radial adalah sebuah bentuk yang ekstrovert yang mengembangkan keluar lingkupnya serta memadukan unsurunsur baik organisasi terpusat maupun linear. Variasi tertentu dari organisai radial adalah pola baling-baling di mana lengan lengan linearnya berkembang dari sisi sebuah ruang pusat berbentuk segi empat atau bujur sangkar.

\section{c. Organiasi cluster}

Komposisi sebuah organisasi terklaster yang memiliki kesamaan baik ukuran, fungsi maupun bentuk, namun tetap tehubung satu sama lain oleh kedekatan atau melalui sejenis alat pengatur visual seperti simetri atau sebuah sumbu.

\section{d. Organisasi grid}

Kekuatan yang mengorganisir suatu grid dihasilkan dari keteraturan dan kontinuitas pola-polanya yang meliputi unsur-unsur yang diorganisir. Sebuah grid dapat mengalami perubahan-perubahan bentuk yang lain.

\section{e. Organisasi terpusat}

Sebuah ruang dominan yang terpusat dengan pengelompokan sejumlah ruang sekunder. Organisasi terpusat dengan bentuk yang relatif padat dan secara geometri teratur dapat digunakan untuk : 1) Menetapkan titik-titik yang menjadi point of interest dari suatu ruang, 2)

Menghentikan kondisi-kondisi aksial, 3) Berfungsi sebagai suatu bentuk obyek di dalam daerah atau volume ruang yang tetap.

Ruang organisasi terpusat memiliki sifat mempersatukan ini umumnya bentuknya teratur dan ukurannya pun cukup besar untuk mengumpulkan sejumlah ruang sekunder di sekeliling garis batasnya. Ruang-ruang sekunder pada organisasi ini dapat saja setara satu sama lain dalam hal fungsi, bentuk, dan ukurannya, serta menciptakan sebuah konfigurasi keseluruhan yang secara geometris teratur dan simetris pada dua buah sumbu atau lebih.

\section{Arsitektur Terapeutik}

Taman dengan konsep healing garden atau taman terapeutik menurut Sprigg dan Weisen (2002) adalah taman yang meningkatkan kualitas lingkungan medis, tidak hanya dapat dinikmati dari aspek desain lanskapnya tetapi juga untuk pelayanan kesehatan. Manfaat taman tersebut dapat memberikan kesembuhan seperti penurunan depresi, memberikan kenyamanan dan memperbaiki mental dan emosi.

Kriteria desain objek rancang diambil dari metode penyembuhan yang diterapkan pada rancangan, poin-poin tersebut adalah: 
Nur Husniah Thamrin, Zakiah Hidayati, Ayu Lestari, Perencanaan Poliklinik Jiwa di Samarinda, Penekanan Pada Organisasi Ruang

a. Care in the community (Rancangan harus dapat mendorong dan mengakomodasi terjadinya interaksi dan sosialisasi).

b. Design for domesticity (Rancangan harus dapat menciptakan dan memberi suasana seperti di rumah).

c. Social valorisation (Rancangan harus dapat menjaga privasi dan keamanan pengguna).

d. Integrated with nature (Rancangan harus dapat memanfaatkan dan memaksimalkan elemen-elemen alami di tapak dan sekitarnya).

Pada kriteria desain poin d, aspek alami sangat diperhatikan. Pada dasarnya, penerapan konsep therapeutic spaces sangat erat hubungannya dengan alam. Terdapat 2 penerapan konsep tersebut pada objek rancang, yaitu:

\section{a. Terapi holtikultura}

Terapi holtikultura menurut yang didefinisikan oleh American Holticultural Therapy Association, adalah kegiatan yang melibatkan seseorang dalam kegiatan tanam-menanam dan berkebun. Terdapat program terapeutik dalam terapi ini yang ditujukan salah satunya untuk korban penyalahgunaan narkoba. Melihat keindahan dan melakukan kontak langsung dengan tanaman dapat memicu ketenangan dan kedamaian, memicu emosi positif, dan mengalihkan fokus dari stres. Oleh karena itu, pada objek rancang disediakan fasilitas area tanam-menanam.

\section{b. Therapeutic garden}

Merupakan taman di ruang luar yang didesain secara spesifik untuk pengguna tertentu (Holowitz, 2012). Taman tersebut dapat bersifat aktif (digunakan berkegiatan) ataupun pasif (dinikmati). Terdapat elemen-elemen yang harus ada di taman tersebut, baik alami maupun terbangun. Elemen-elemen tersebut adalah:
1). Alami: Tanaman yang familiar, tanaman yang menarik burung dan kupu-kupu, Tanaman hias, Sayur-sayuran, Tanaman musiman, Tanah, Matahari dan naungan alami, Angin dan hujan

2) Terbangun: Patio/teras, Selasar, Tempat duduk, Pencahayaan lanskap, Naungan, Keran air, Outlet listrik outdoor

\section{METODE PENELITIAN}

Metode Umum dan Tahapan Perancangan

Metode yang digunakan dalam perencanaan dan perancangan dalam pembangunan Poliklinik Jiwa di Samarinda dengan penekanan pada organisasi ruang, meliputi metode deskriptif yaitu dengan menggambarkan suasana atau menganalisis suatu hasil penelitian yang kemudian disimpulkan.

1. Identifikasi Masalah

2. Pengumpulan Data

3. Analisis Data

4. Konsep

5. Metode Pengumpulan Data

\subsection{Data Primer}

1. Survei Lapangan

Survei lapangan dilakukan di Rumah Sakit Jiwa Atma Husada Mahakam, Rumah Sakit Siloam Balikpapan, dan Klinik Famro. Pada survei lapangan ini untuk mengetahui ukuran ruang dan juga nama-nama ruang yang ada di dalam Rumah Sakit Jiwa Daerah Atma Husada Mahakam, Rumah Sakit Siloam Balikpapan, dan Klinik Famro yaitu dengan meminta data fisik berupa dokumen sarana rumah sakit.

2. Wawancara

Wawancara merupakan data atau informasi yang didapat melalui interview atau bertanya langsung dengan orangorang yang terkait yaitu penanggung jawab, dan dibagian pelayanan.

\subsection{Data Sekunder}
a. Studi Literatur
b. Studi Perbandingan 


\subsection{Metode Pengolahan Data}

Adapun langkah-langkah dalam pengolahan data adalah sebagai berikut :

1. Membuat analisis perancangan

2. Membuat konsep perancangan,

3. Membuat transformasi desain sebelum memulai gambar kerja.

4. Membuat Rencana Anggaran Biaya (RAB) dan Rencana Kerja dan Syarat (RKS).

\section{HASIL DAN PEMBAHASAN}

Berdasarkan contoh metode diatas maka Perencanaan Poliklinik Jiwa di Samarinda Penekanan Pada Organisasi Ruang menyesuaikan dengan aturan - aturan metode tersebut. Langkah pertama melakukan Analisis yaitu analisis peruangan yang terdiri dari analisis kegiatan seperti kegiatan apa saja yang dilakukan oleh pengguna bangunan serta klasifikasi pengguna, analisis kebutuhan dan besaran ruang pada bagian ini menentukan seberapa luas ruang yang dibutuhkan serta dapat menampung apa saja ruangan tersebut, dan analisis penzoningan yaitu menentukan apakah ruang tersebut bersifat private, semi private / public, public maupun service. Adapun hasil analisis peruangan sebagai berikut.
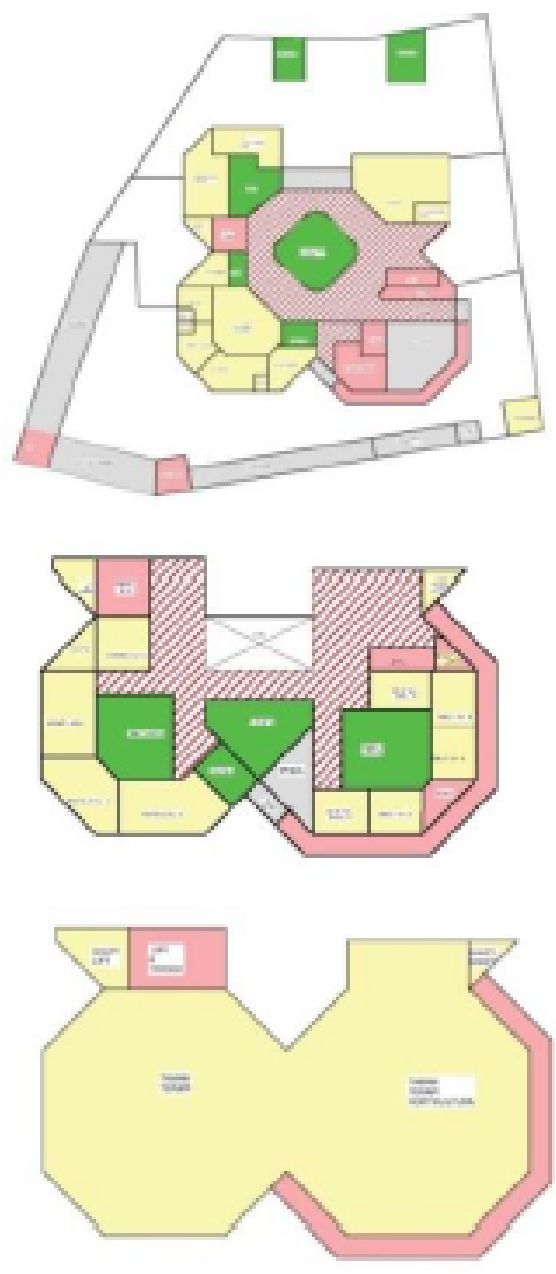

Keterangan :

$\square$ : service

\section{: private}

Gambar 1. Blockplan lantai dasar, lantai 1 dan lantai 2

Tahap kedua adalah gubahan massa/ bentuk merupakan sesuatu yang berhubungan dengan filosofi bangunan baik dari tampak/ fasade bangunan atau dari bentukan lainnya yang menjadi sumber inspirasi bagi bangunan Poliklinik Jiwa. 
Nur Husniah Thamrin, Zakiah Hidayati, Ayu Lestari, Perencanaan Poliklinik Jiwa di Samarinda, Penekanan Pada Organisasi Ruang

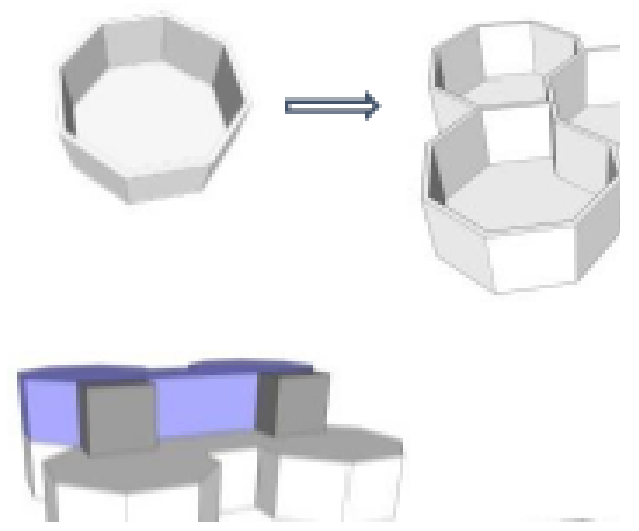

Gambar 2. Analisis Gubahan Massa

1. Pada lantai dasar merupakan penggabungan dari beberapa bentuk hexagon dengan bentuk hexagon bagian tengah digunakan sebagai area kedatangan.

2. Hexagon yang berada di tengah pada lantai dasar merupakan pusat dari bangunan.

3. Pada lantai satu, bentuk serupa pada lantai dasar diaplikasikan namun hanya setengah dari lantai satu yang diteruskan ke atas.

4. Pada lantai satu juga ditambahkan bentukan pada bagian depan bangunan.

5. Pada lantai dua atau topfloor akan digunakan sebagai taman.

6. Masing-masing dari lantai memiliki tinggi 4,5 meter.

\section{Analisis Organisasi Ruang}

Penataan pola organisasi ruang dapat menentukan kenyamanan dan penyembuhan bagi semua pengguna Poliklinik Jiwa karena terdapat banyak ruangan dengan kebutuhan yang berbeda-beda. Oleh karena itu, akan dilakukan analisis untuk menentukan organisasi ruang apa yang sesuai dengan bangunan Poliklinik Jiwa.
Tabel 1. Pemilihan pola organisasi ruang

\begin{tabular}{|c|c|c|c|c|c|c|}
\hline $\begin{array}{l}N \\
0 .\end{array}$ & $\begin{array}{c}\text { Dasar } \\
\text { Pertimbangan }\end{array}$ & Linear & Radial & $\begin{array}{l}\text { Spsit } \\
\text { all }\end{array}$ & Terpusat & Grid \\
\hline 1. & $\begin{array}{l}\text { Pola sitholasi tidak } \\
\text { memecah }\end{array}$ & 3 & 1 & 1 & 3 & 1 \\
\hline 2. & $\begin{array}{l}\text { Mernabimalion } \\
\text { pertemuan anter } \\
\text { aser }\end{array}$ & 2 & 1 & 1 & 3 & 1 \\
\hline 3. & $\begin{array}{ll}\text { Memiliki } & \text { batas } \\
\text { ruang } & \text { yang } \\
\text { mitima! } & \\
\end{array}$ & 1 & 1 & 2 & 3 & 1 \\
\hline 4. & $\begin{array}{l}\text { Menudahkan } \\
\text { pergamasan }\end{array}$ & 2 & 1 & 1 & 3 & 1 \\
\hline & Tota! & & 4 & 5 & 12 & 4 \\
\hline
\end{tabular}

Pola organisasi ruang yang akan diterapkan pada bangunan Poliklinik Jiwa adalah pola organisasi ruang terpusat dan linier. Kelebihan pola organisasi ruang terpusat dapat memberikan pertemuan user atau overlap yang maksimal sehingga pasien dapat berinteraksi dan bersosialisasi, juga pola ini dapat memudahkan pengawasan karena tingginya tingkat keamanan bagi pasien. Sedangkan dari pola sirkulasi linear adalah mudah diakses terutama bagi pengunjung atau pasien, namun sulit untuk memecah keramaian. Pada bangunan Poliklinik Jiwa nantinya akan menerapkan penggabungan antar kedua pola tersebut.

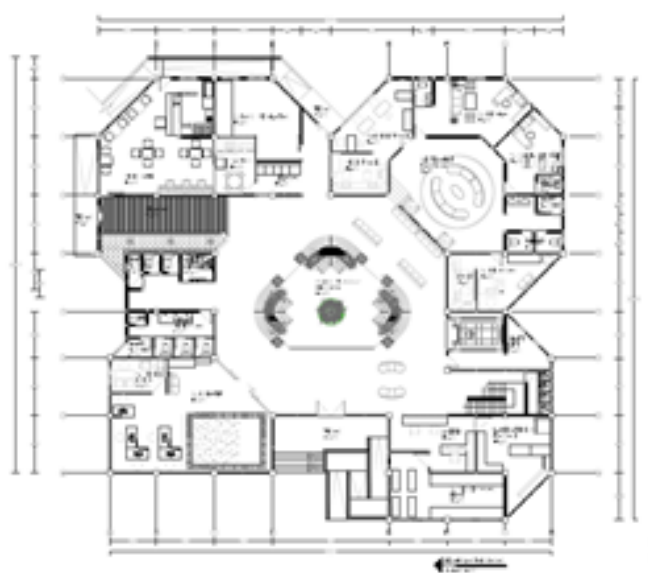

Gambar 3. Denah Lantai Dasar 
Vol. 7, No. 1, Oktober 2019

Poliklinik Jiwa di Samarinda menggunakan konsep peruangan organisasi ruang terpusat. Dengan konsep organisasi ruang terpusat ini yang pada umumnya memiliki sedikit jalur sirkulasi sehingga diharapkan dapat memunculkan overlap agar penggunanya dapat berinteraksi lebih sering. Di dalam komposisinya yang hampir sama besar dan tersusun rapi dengan kolom yang teratur jadi memudahkan dalam pembangunan dan sirkulasi juga mudah/tidak membuat pusing para pengunjung poliklinik.

Pada lantai dasar terdapat taman indoor yang berada tepat ditengah. Taman indoor digunakan sebagai ruang bersantai serta ruang tunggu bagi pengunjung. Taman indoor ini menjadi pusat kegiatan dari seluruh aktifitas di lantai dasar

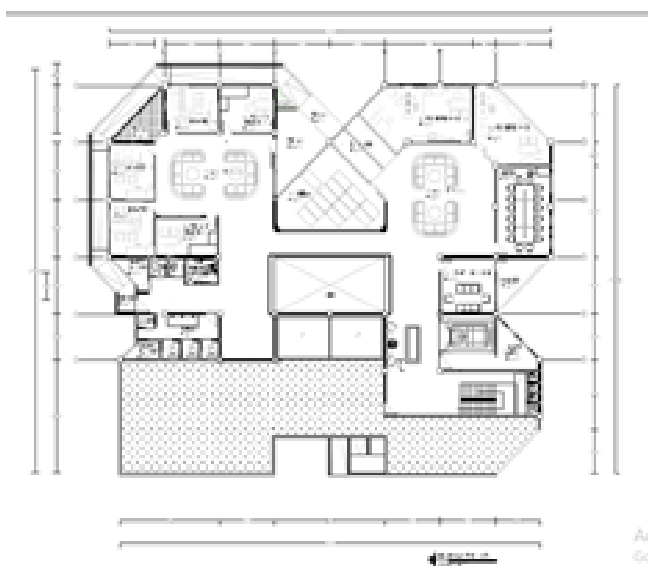

Gambar 4. Denah Lantai Satu

Lantai satu memiliki kegiatan yang dikelompokkan dengan kegiatan lain yang bersifat private. Lantai ini dibaut menjadi lantai yang bersifat private untuk menjaga keamanan dan kenyaman pasien saat melakukan terapi serta memberikan ruang bagi pendamping untuk dapat bersantai.

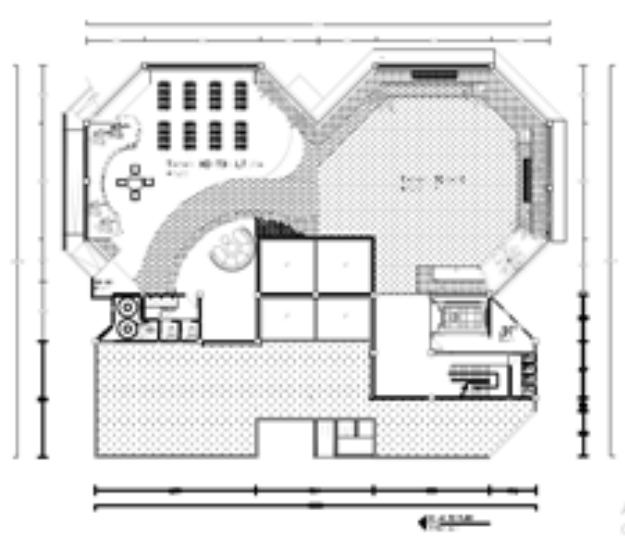

Gambar 5. Denah Lantai Dua atau Roofgarden

Roof garden dibuat di lantai rooftop yang digunakan sebagai taman terapi outdoor bagi pasien. Pada lantai ini terdapat taman terapi aktifitas dan taman hortikultura untuk kegiatan tanam-menanam serta terdapat area bersantai.

Sirkulasi dari roofgarden pun dibuat memutar untuk mendukung para pasien memiliki keinginan lebih untuk bersosialisasi.

\section{Analisis Konsep Terapeutik}

Poliklinik Jiwa di Samarinda memberikan beberapa macam terapi, salah satunya terapi yang melibatkan pasien dengan ruang luar atau alam. Konsep taman terapeutik yang didesain khusus untuk penyembuhan pasien dengan beberapa unsur.

Taman terapeutik diterapkan dalam bangunan Poliklinik Jiwa yaitu ada dua macam, pertama adalah taman hortikultura dan taman aktifitas. Taman hortikultura digunakan sebagai area tanam-menanam bagi pasien sedangkan Taman aktifitas merupakan taman yang lapang yang digunakan untuk aktifitas fisik bagi pasien seperti olahraga, terapi fisioterapi dsb.

Selain itu, ada beberapa unsur yang digunakan dalam taman terapeutik ini yaitu unsur alam dan unsur terbangun. Adapun unsur tersebut sebagai berikut :

1. Penggunaan vegetasi-vegetasi yang familiar seperti pohon palem, teh-tehan. 
Nur Husniah Thamrin, Zakiah Hidayati, Ayu Lestari, Perencanaan Poliklinik Jiwa di Samarinda, Penekanan Pada Organisasi Ruang

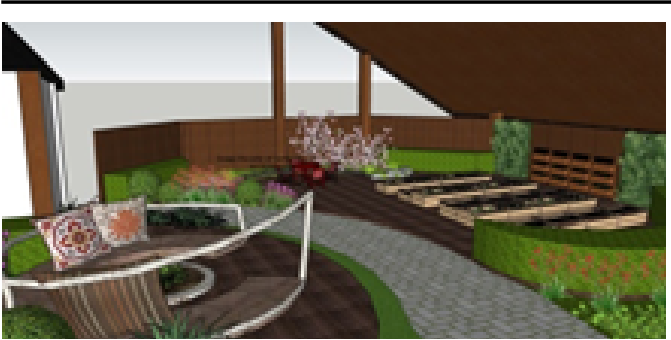

Gambar 6. Taman Hortikultura

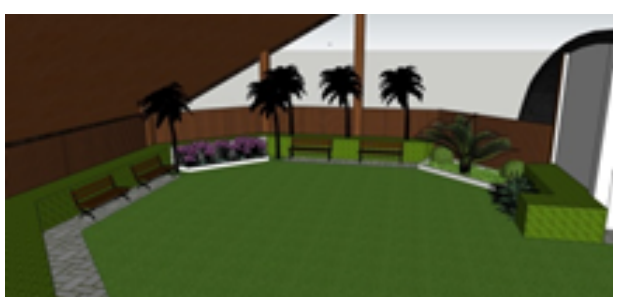

Gambar 7. Taman Aktifitas

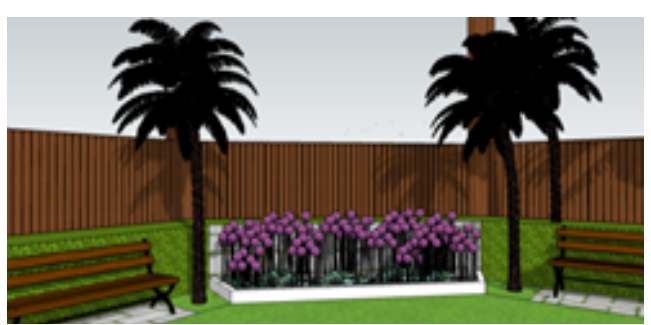

Gambar 8. Penerapan KonsepTerapeutik pada Vegetasi

Menanam vegetasi yang memiliki wewangian untuk membuat pasien merasa tenang seperti pohon palem, daun pandan, bunga kamboja dan allium.

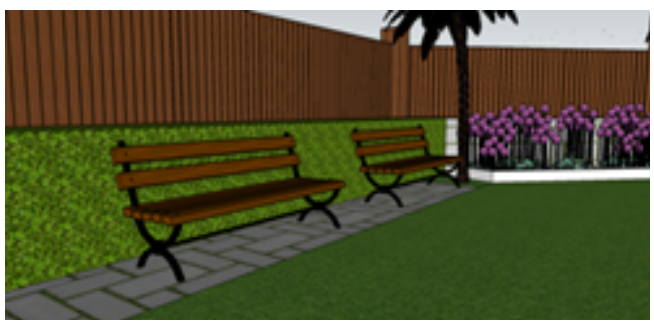

Gambar 9. Penerapan Konsep Terapeutik pada Area Istirahat
Pengunaan bangku taman yang tidak terlau keras atau yang tidak bisa dilepas bagi pasien seperti kursi kayu dan atau tempat duduk permanen permanen dari beton yang telah dilapisi dengan material lunak.

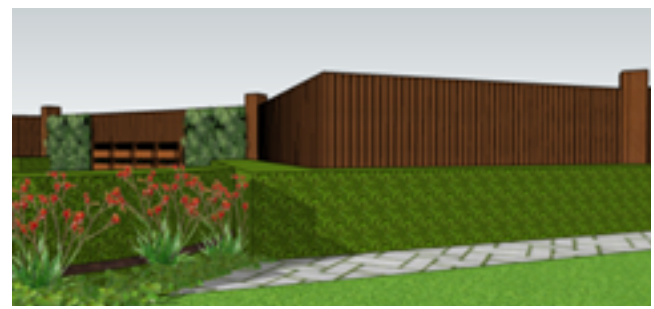

Gambar 10. Penerapan Konsep Terapeutik pada Keamanan Bangunan

Penggunaan pagar kayu setinggi 2.5 meter yang disusun secara vertikal agar pasien tidak dapat memanjat. Memberikan atap transparan seperti kaca agar pasien tidak merasa dikurung dan harus dipastikan tidak ada pijakan agar pasien tidak terpicu untuk memanjat.

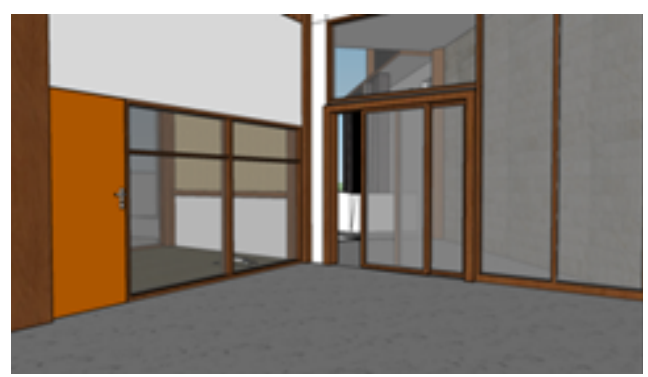

Gambar 11. Penerapan Konsep Terapeutik pada Interior Bangunan

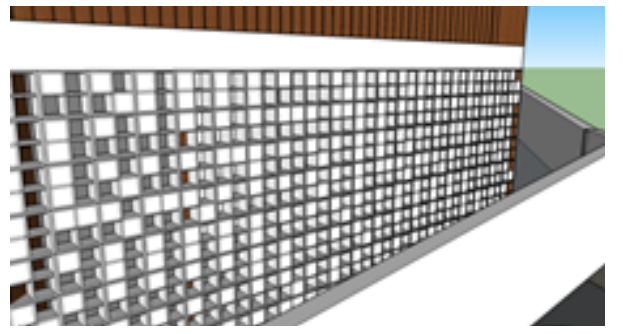

Gambar 12. Penerapan Konsep Terapeutik pada Eksterior Bangunan 
Vol. 7, No. 1, Oktober 2019

Tingkat keamanan yang tinggi mengharuskan setiap tempat dapat memiliki akses pandang secara langsung dengan tempat lain sehingga diperlukan dinding tidak masif seperti dinding kaca atau rooster.

Penggunaan pagar kayu setinggi 2.5 meter yang disusun secara vertikal agar pasien tidak dapat memanjat. Memberikan atap transparan seperti kaca agar pasien tidak merasa dikurung dan harus dipastikan tidak ada pijakan agar pasien tidak terpicu untuk memanjat.

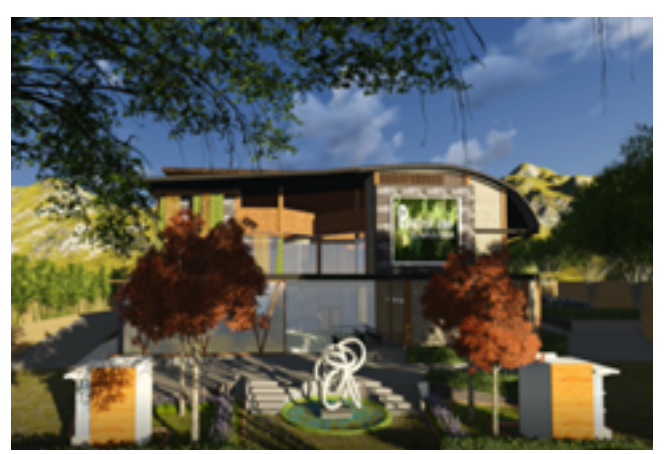

Gambar 13. Penerapan Konsep Terapeutik pada Gaya Bangunan

Penerapan gaya arsitektur tropis pada bangunan dapat memberikan kesan terapeutik karena suasana yang didapatkan seperti rumah. Penggunaan material-material alam yang umumnya dijumpai seperti kayu dan batu alam dapat membuat pasien tidak merasa asing ketika berada di dalam maupun luar bangunan.

\section{KESIMPULAN DAN SARAN}

\subsection{Kesimpulan}

Berdasarkan hasil analisis yang telah dilakukan dengan pendekatan organisasi ruang dan konsep arsitektur terapeutik dapat disimpulkan bahwa organisasi ruang yang cocok untuk bangunan Poliklinik Jiwa adalah organisasi ruang terpusat yang diatur berdasarkan kepentingan dan fungsi dari setiap ruangan.

Sedangkan, konsep arsitektur terapeutik yang dapat diterapkan pada bangunan Poliklinik Jiwa adalah sebagai berikut.
1. Care in the the community (Rancangan harus dapat mendorong dan mengakomodasi terjadinya interaksi dan sosialisasi). Dalam hal ini penerapan organisasi ruang terpusat pada lantai dasar dan roofgarden.

2. Design for domesticity (Rancangan harus dapat menciptakan dan memberi suasana seperti di rumah).

a. Penerapan pada gaya bangunan modern tropis

b. Penerapan pada material bangunan

3. Social valorisation (Rancangan harus dapat menjaga privasi dan keamanan pengguna)

a. Penerapan pada keamanan bangunan

b. Penerapan pada interior bangunan

4. Integrated with nature (Rancangan harus dapat memanfaatkan dan memaksimalkan elemen-elemen alami di tapak dan sekitarnya)

a. Taman terapeutik (taman hortikultura dan taman aktifitas).

b. Penerapan tanaman yang familiar .

c. Penerapan taman yang memiliki wewangian.

d. Penerapan pada area istirahat.

\subsection{Saran}

Perancangan klinik skizofrenia juga sebaiknya melihat dari segi sirkulasi pencahayaan dan penghawaan alami, serta pendekatan psikologis untuk menata baik interior maupun eksterior. Kedepannya saat penulisan atau perancangan selanjutnya dapat menitik beratkan pada rancangan-rancangan interior bangunan klinik. 
Nur Husniah Thamrin, Zakiah Hidayati, Ayu Lestari, Perencanaan Poliklinik Jiwa di Samarinda, Penekanan Pada Organisasi Ruang

DAFTAR PUSTAKA

Arif, Iman Setiadi (2006). Skizofrenia Memahami Dinamika Keluarga Pasien. Bandung : PT. Refika Aditama.

Ching, Francis D.K. (2008). Arsitektur : Bentuk, Ruang \& Tatanan Edisi Ketiga. Jakarta : Penerbit Erlangga.

Mitrione, Steve, Larson Jean. (2007). Healing by Design : Healing Gardens and Therapeutic Landscapes. Minnesota : Inform Design.

\section{Referensi Internet}

Azhari, Nabilla Fadlina, Rachmawati, Murni. (2017). Penggunaan Pendekatan Healing Architecture dan Konsep Therapeutic Spaces pada Rancangan Fasilitas Rehabilitasi Sosial bagi Korban Narkoba. Jurnal Sains dan Seni POMITS, 2337-3520.

Dewi, Raden Roro Monica Synthia Permata, Kusmarini, Yusita, Rakhmawati, Anik. (2018). Identifikasi Penerapan Biophilic Design pada Interior Rumah Sakit. Jurnal Intra Vol. 6. 687-697.

Indira, Nurdini Elsa, Wardhana, Mahendra, Indraprasti, Anggri. (2017). Desain Interior Rumah Sakit Jiwa Dr. Radjiman Wediodiningrat Lawang Malang. Jurnal Sains dan Seni Vol.6. 2337-3520.

Saraswati, Titien, Haryangsah, Ranu. (2003). Pengaruh Tata Ruang Bangsal Rumah Sakit Jiwa Terhadap Keselamatan dan Keamanan Pasien. Jurnal Dimensi Teknik Arsitektur Vol. 31. 111-119.

Sulistyorini, Nopyawati. (2013). Hubungan Pengetahuan Tentang Gangguan Jiwa Terhadap Siap Masyarakat Kepada Penderita Gangguan Jiwa di Wilayah Kerja Puskesmas Colomadu I. Naskah Publikasi Universitas Muhammadiyah Surabaya.

Zahnia, Siti, Sumekar, Dyah Wulan. (2016). Kajian Epidermologis Skizofrenia. MAJORITY Volume 5. 